\title{
Diet and lifestyle interventions in postpartum women in China: study design and rationale of a multicenter randomized controlled trial
}

\author{
Wei Bao ${ }^{1}$, Aiguo Maํ․ Limei Mao ${ }^{3}$, Jianqiang Lai ${ }^{4}$, Mei Xiao ${ }^{5}$, Guoqiang Sun ${ }^{5}$, Yingying Ouyang ${ }^{1}$, Shuang Wu',
} Wei Yang ${ }^{1}$, Nanping Wang ${ }^{6}$, Yanting Zhao', Juan Fu', Liegang Liü ${ }^{1 *}$

\begin{abstract}
Background: "Doing the month", or "sitting month", is a traditional practice for postpartum women in China and other Asian countries, which includes some taboos against well-accepted healthy diet and lifestyles in general population. Previous studies have shown this practice may be associated with higher prevalence of postpartum problems. The current multicenter randomized controlled trial (RCT) aims to evaluate outcomes of diet and lifestyle interventions in Chinese postpartum women.

Methods/Design: The current multicenter RCT will be conducted in three representative areas in China, Shandong province, Hubei province and Guangdong province, which locate in northern, central and southern parts of China, respectively. Women who attend routine pregnancy diagnosis in hospitals or maternal healthcare centers will be invited to take part in this study. At least 800 women who meet our eligibility criteria will be recruited and randomly assigned to the intervention group $(n>=400)$ and the control group $(n>=400)$. A three-dimension comprehensive intervention strategy, which incorporates intervention measures simultaneously to individual postpartum woman, their family members and community environment, will be utilized to maximize the effectiveness of intervention. Regular visiting and follow-up will be done in both group; nutrition and healthrelated measurements will be assessed both before and after the intervention.

Discussion: To our knowledge, this current study is the first and largest multicenter RCT which focus on the effectiveness of diet and lifestyle intervention on reducing the incidence rate of postpartum diseases and improving health status in postpartum women. We hypothesize that the intervention will reduce the incidence rates of postpartum diseases and improve nutrition and health status due to a balanced diet and reasonable lifestyle in comparison with the control condition. If so, the results of our study will provide especially important evidence for changes in both the concept and action of traditional postpartum practice in China.
\end{abstract}

Trial Registration: ClinicalTrials.gov ID NCT01039051.

\section{Background}

The postpartum period, or puerperium, which starts about an hour after the delivery of the placenta and includes the following six weeks, covers a critical transitional time for a woman, her newborn and her family, on a physiological, emotional and social level. However, the postpartum period is often neglected by maternity

\footnotetext{
* Correspondence: Igliu@mails.tjmu.edu.cn

'Department of Nutrition and Food Hygiene and MOE Key Lab of Environment and Health, School of Public Health, Tongji Medical College, Huazhong University of Science \& Technology, 13 Hangkong Road, Wuhan 430030, PR China
}

care in both developing and developed countries [1]. In addition, women's needs during this period have been all too often eclipsed by the attention given to pregnancy and birth [2]. The lack of postpartum care ignores the fact that the majority of maternal deaths and disabilities occur during the postpartum period and that early neonatal mortality remains high $[3,4]$.

"Doing the month", or "sitting month", is a wellaccepted and obeyed traditional practice among postpartum women and their families in China, which is also common in other Asian countries, such as Korea, 
Thailand, and Singapore [5-7]. According to traditional customs, women who are "doing the month" are advised to lie in bed all the time with doors and windows closed, and consume plenty of eggs or meat, drink bowels of chicken soup, brown sugar water, and millet gruel every day, while avoid eating any raw and cold food (mainly refers to fruits, vegetables), because cold food were thought to be unfavorable for postpartum recovery [8-10]. This practice seems to be believed more or less by almost all Chinese population worldwide, rather than only by local people in China mainland. Immigration studies showed that Chinese women who immigrated to Australia, Canada or United States still think that the traditional puerperium practice of "doing the month" is very important, and this belief is not subject to their level of education, acculturation level and the duration of immigration [11-14].

We have ever conducted a preliminary study in three regions of Hubei province in China to investigate prevalence of puerperium practice and their effect on postpartum women's health $[15,16]$. We found that $18 \%$ of women never ate vegetables, $78.8 \%$ never ate fruit and $75.7 \%$ never drank milk during the puerperium while, in contrast, the consumption of eggs and brown sugar were as high as $365.0 \mathrm{~g} / \mathrm{d}$ and $81.3 \mathrm{~g} / \mathrm{d}$ in rural postpartum women, which is associated with postpartum problems including constipation, backaches, breast problems, oral diseases and anemia, et al [15].

However, as indicated in a Cochrane systematic review [17], evidence is too limited at present to confirm the effect of diet and lifestyle modification on outcomes for the postpartum women and their offspring. Therefore, we initiate this multicenter randomized controlled trial (RCT) with large-scale sample size to elucidate whether a diet and lifestyle intervention can improve the health status in Chinese postpartum women.

\section{Methods/Design \\ Objectives}

This multicenter RCT is designed to assess the effectiveness of a diet and lifestyle intervention in postpartum women in China, including a short-term effect on reducing health problems during puerperium period and a long-term effect on improving health status in women and their offspring over a two-year period.

\section{Study Population}

The current multicenter study will be conducted in three representative areas in China, Shandong province, Hubei province and Guangdong province, which locate in northern, central and southern parts of China, respectively. Women who attend routine pregnancy diagnosis in hospitals or maternal healthcare centers will be invited to take part in the randomized controlled intervention trial.

\section{Sample size}

Sample size has been calculated as the following formula [18]:

$$
N=\frac{\left[Z_{\alpha / 2} \sqrt{2 \bar{p}(1-\bar{p})}+Z_{\beta} \sqrt{p_{1}\left(1-p_{1}\right)+p_{2}\left(1-p_{2}\right)}\right]^{2}}{\left(p_{1}-p_{2}\right)^{2}} \text {, in which }
$$

$p_{1}$ indicates incidence rate in control group, $p_{2}$ indicates incidence rate in intervention group and $\bar{p}$ indicates average of $p_{1}$ and $p_{2} . Z_{\alpha / 2}$ is 1.96 when significance level $(\alpha)$ is 0.05 and $Z_{\beta}$ is 1.64 for power $(1-\beta)$ is 0.90 .

Take constipation, a typical diet-related digestive disorder, for example. The incidence rate of constipation in our previous study is $20.95 \%$ in the control group [16]. We aim to reduce the incidence rate by $50 \%$, which is $10.475 \%$, the sample size $\mathrm{N}=$ $\frac{[1.96 \sqrt{2 \times 0.157125 \times 0.842875}+1.64 \sqrt{0.2095 \times 0.7905+0.10475 \times 0.89525}]^{2}}{(0.2095-0.10475)^{2}}=$

$309.89 \approx 310$ for each group. On the basis of the above calculation, a sample size of 800 participants (400 in the intervention group and 400 in the control group) has been determined, considering a certain attrition rate. This sample size is adequate, with statistical power $>80 \%$, for nearly all the major outcomes, including changes in nutritional status and health status.

\section{Recruitment process}

The flowchart of participant's recruitment process and trial design is summarized in figure 1 . Pregnancy women that are willing to take part in our study will be checked by our eligibility criteria. The eligibility criteria for enrollment includes: 1) healthy pregnant women; 2) at their third trimester; 3 ) had at least three routine examinations at these antenatal clinics [16]. A written consent form will be assigned by each woman to confirm her willingness to participate, and then baseline data will be collected by a questionnaire survey (main components shown in Table 1) and a consequent anthropometric measurement.

\section{Randomization}

Recruited women will be randomly allocated to either intervention group or control group according to a random number generated by a computer-based procedure. Then, a unique code for each participating woman and her allocation will be recorded.

\section{Blinding}

Although it is impossible to ensure blinding for intervention conductor and the participating women, we will ensure blinding for the outcome measurements and biochemical analyses by independent examiners unaware of group allocation. Participants cannot be blinded for the 


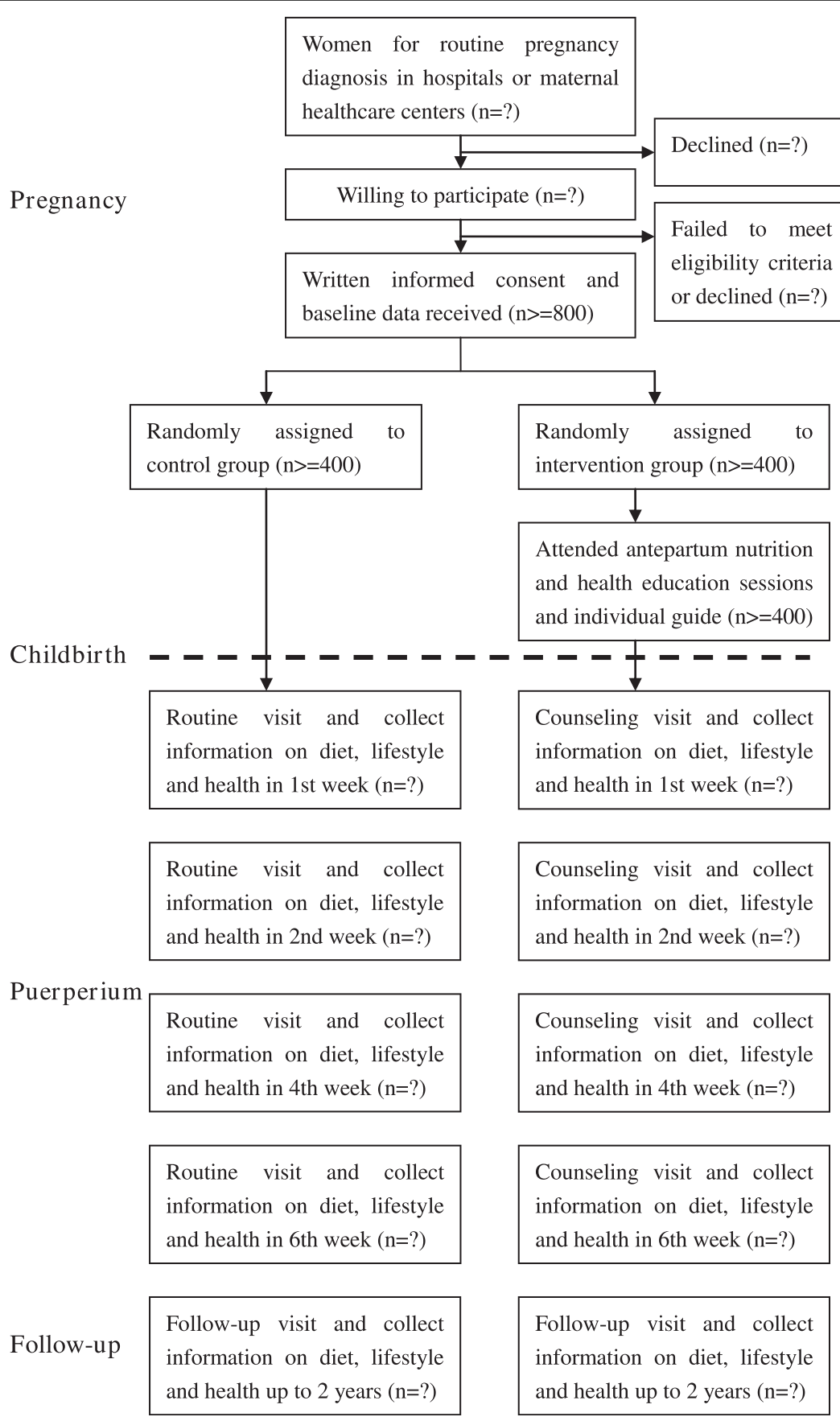

Figure 1 Flowchart of participant's recruitment and trial design.

intervention, but they are asked not to reveal information about their allocation to the examiners. The key of coding concerning group assignment is only known by the programmer of the database that is used during the study.

\section{Interventions}

On the basis of our previous study in postpartum women from Hubei province of China and the latest
WHO recommendation [19], we have formed a set of recommendations for women's diet and lifestyle during the postpartum period, which is the guideline for the current intervention study. A comparison between traditional practices for "doing the month" and expected diet and lifestyle that we advocated during the postpartum period are shown in Table 1 . It is obvious that our guideline emphasizes the importance of increasing 
Table 1 Overview of the Questionnaires

\begin{tabular}{ll}
\hline Categories & Items \\
\hline General information & Age, residence, occupation, education level, family economic situation, height, body weight, diagnosis of \\
& diseases, family history of diseases \\
\hline Basic knowledge in nutrition and health & - Food guide pyramid knowledge \\
& - Nutrient-food association knowledge \\
& - Special nutritional requirement during postpartum period \\
\hline Food intake & - Frequency and amount of cereals intake \\
& - Frequency and amount of vegetables intake \\
& - Frequency and amount of fruits intake \\
& - Frequency and amount of meat intake \\
& - Frequency and amount of eggs intake \\
& - Frequency and amount of milk and its products intake \\
& - Frequency and amount of soybean and its products intake \\
& - Frequency and amount of brown sugar intake \\
& - Frequency and amount of dietary oil intake \\
& - Frequency and amount of salt intake \\
& - Frequency and amount of other substance intake (alcohol, strong tea, coffee, et al.) \\
\hline Health-related behaviors and Physical & Teeth brushing, Bathing and Hair washing \\
Ventivities & Always lie in the bed or Get up for wandering \\
& Maternal keep-fit exercises \\
& Light physical activity or Heavy physical activity \\
Basking in the sun
\end{tabular}

Table 2 Comparison between Traditional Practices for "Doing the Month" and Expected Diet and Lifestyle that We Advocated during the Postpartum Period

\begin{tabular}{|c|c|c|}
\hline & $\begin{array}{l}\text { Traditional practices for "doing the } \\
\text { month" }\end{array}$ & Expected diet and lifestyle during the postpartum period \\
\hline \multirow[t]{9}{*}{ Dietary Habits } & Eat plenty of food & Increase total amount of food in accordance with energy expenditure \\
\hline & Meat-based diet components & Diverse food with both animal foods and plant-derived foods \\
\hline & $\begin{array}{l}\text { Eat "hot" or "Yang" food (referred to meat, } \\
\text { sugar, eggs, chicken soup, et al) }\end{array}$ & $\begin{array}{l}\text { Ensure sufficient protein intake from fish, poultry meat, lean meat and eggs } \\
\text { Enjoy milk, soybeans, or their products daily Restrict fat intake from animal foods }\end{array}$ \\
\hline & $\begin{array}{l}\text { Avoid "cold" or "Yin" food (referred to fruit, } \\
\text { vegetables, cold water, et al) }\end{array}$ & $\begin{array}{l}\text { Eat more vegetables fruits and nuts in various species } \\
\text { Drink sufficient quantity of water and juice every day } \\
\text { Have liquid food, such as non-greasy soup, before or between meals }\end{array}$ \\
\hline & Keep dietary taboos in mind & $\begin{array}{l}\text { Advise the woman against dietary taboos about foods which are nutritionally } \\
\text { healthy. Reassure the mother that she can eat any normal foods. } \\
\text { Talk to family members such as husband and mother-in-law, to encourage them } \\
\text { to help } \\
\text { ensure the woman eats enough. }\end{array}$ \\
\hline & & Eat more foods rich in dietary fiber \\
\hline & & Supplement with vitamins and minerals \\
\hline & & Restrict salt consumption in diet \\
\hline & & Avoid drinking alcohol, strong tea or coffee \\
\hline \multirow{4}{*}{$\begin{array}{l}\text { Other Health- } \\
\text { related behaviors }\end{array}$} & Never brush teeth & Brush teeth twice per day \\
\hline & Never bathe or wash hair & $\begin{array}{l}\text { If possible, take a shower every day in a warm room and wash hair at least once a } \\
\text { week }\end{array}$ \\
\hline & Shut well all windows or doors all the time & $\begin{array}{l}\text { Ventilate regularly, but avoiding the cold wind blowing directly to the mother and } \\
\text { child }\end{array}$ \\
\hline & $\begin{array}{l}\text { Always lie in bed without any physical } \\
\text { activity almost all day and night }\end{array}$ & $\begin{array}{l}\text { Do maternal keep-fit exercises and increase physical activities gradually to maintain } \\
\text { a healthy weight }\end{array}$ \\
\hline
\end{tabular}


consumption of vegetables and fruits, which is regard as a diet taboo for postpartum women in traditional Chinese practice. In addition, it also emphasizes the importance of maintaining energy balance through reducing excessive energy from meat, eggs and brown sugar and increasing energy expenditure from appropriate physical activity, such as doing maternal keep-fit exercises.

In the past decades, social ecological models have been increasingly used to formulate intervention strategies in comprehensive consideration, because simple interventions are unlikely to work on their own and the development of effective interventions requires strategies that affect multiple settings simultaneously [20]. As shown in Figure 2, a panel of environmental factors that influence the knowledge, belief and practice of postpartum women (the core) has been identified. Microsystem, mainly referred to family members of the individual woman, is crucial immediate environmental factors that should be considered in priority. Exosystem, including surrounding people, such as peers, friends, colleagues, neighbors and care physicians, and sources of knowledge, such as book, magazines, TV show, radio and internet, does not usually directly interact, but that can still affect the individual woman. In addition, we have to consider macrosystem, including history, culture, laws, ethnics, social conditions and economic systems, to give a personalized guide to individual postpartum woman. Previous studies by us and other groups have suggested that main influence factors on the diet and lifestyle of a postpartum woman include the woman's knowledge about postpartum nutrition and health care, the woman or her husband's educational level and family income levels, and the traditional concept learned from her mother in-law (49.4\%), mother (34.0\%), books and magazines $(16.5 \%)$, relatives (14.3), friends or colleagues $(12.6 \%)[15,21]$.

Therefore, we have formulated a three-dimension comprehensive intervention strategy (Table 3), which incorporates intervention measures simultaneously to individual postpartum woman, their family members and community environment to maximize the effectiveness of our multicenter trial. For individual postpartum woman, we will set antepartum participatory training courses, provide specially prepared brochures and supporting VCD, set up a specialized counseling hotline and give individual bedside guidance after birth. For their family members, we will invite every postpartum woman's husband and mother to take part in workshops or seminars, making them know some basic knowledge of postpartum care, and persuading them to promote adoption of the diet and lifestyle we advocated by the postpartum woman. For community environment, we will put up posters about basic knowledge of postpartum care in the community bulletin boards for general population educating and mobilize community leaders and heads from and maternal and child health centers for maximum support.

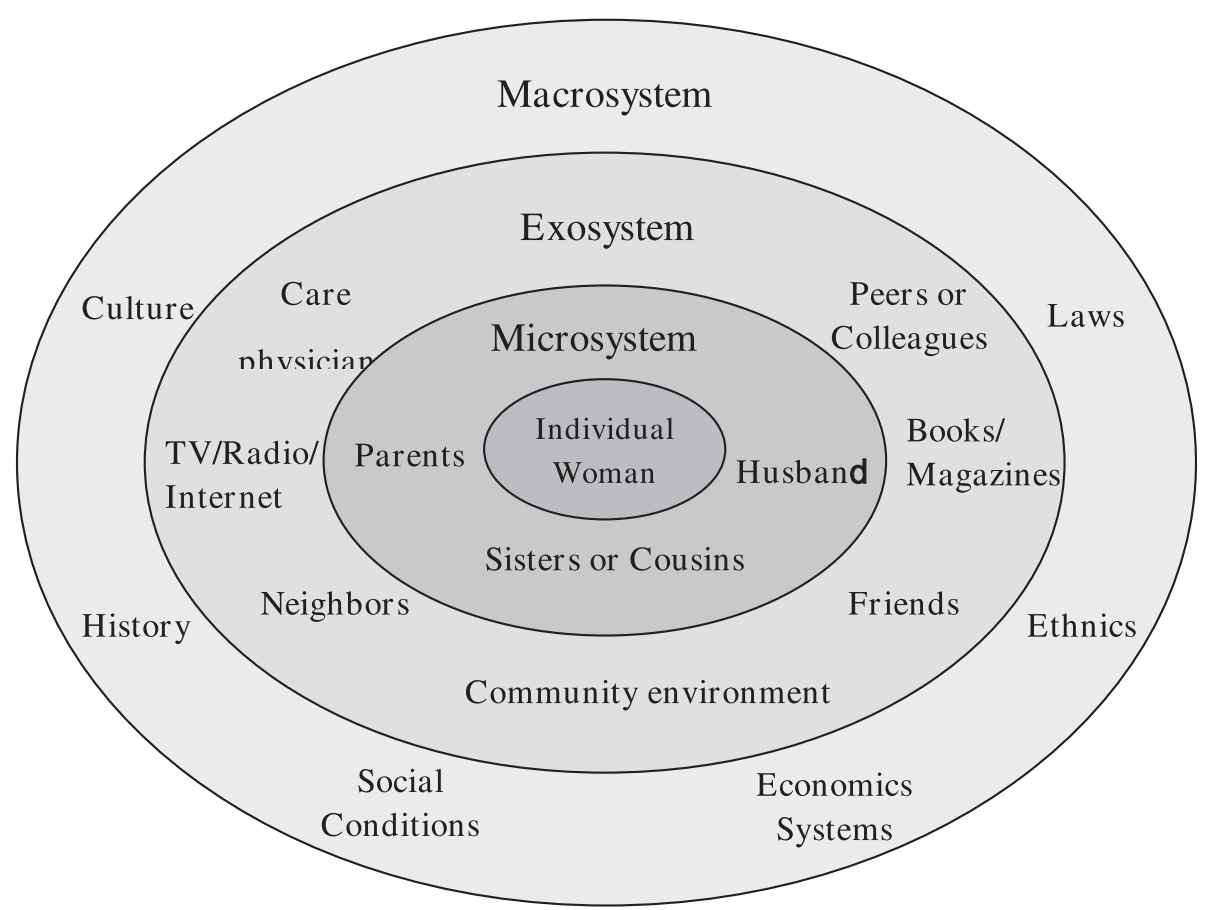

Figure 2 Social Ecological Model showing potential factors that influence postpartum women's belief and practice. 
Table 3 Summary of our three-dimension comprehensive intervention strategy

\begin{tabular}{|c|c|c|}
\hline Dimensions & Subjects & Strategies and Measures \\
\hline 1 & $\begin{array}{l}\text { Postpartum } \\
\text { woman }\end{array}$ & $\begin{array}{l}\text { - Participatory training for woman who expects to childbirth with } 1 \text { month } \\
\text { - Providing specially prepared release of "Chinese women's postpartum reasonable diet and lifestyle program" } \\
\text { (Universal Edition) and supporting VCD, to facilitate self-learning at home } \\
\text { - Setting up a specialized counseling hotline to answer the questions from postpartum woman and their family } \\
\text { members } \\
\text { - Individual bedside guidance for postpartum woman, focusing on how to correctly adjust her diet and life style } \\
\text { during postpartum period }\end{array}$ \\
\hline 2 & $\begin{array}{l}\text { Family } \\
\text { members }\end{array}$ & $\begin{array}{l}\text { Inviting every postpartum woman's husband and mother to take part in workshops or seminars, making them know } \\
\text { some basic knowledge of postpartum care, and persuading them to promote adoption of the diet and lifestyle we } \\
\text { advocated by the postpartum woman }\end{array}$ \\
\hline 3 & $\begin{array}{l}\text { Community } \\
\text { support }\end{array}$ & $\begin{array}{l}\text { - General population educating via putting up posters about basic knowledge of postpartum care in the community } \\
\text { bulletin boards } \\
\text { - Mobilizing community leaders and heads from and maternal and child health centers for maximum support }\end{array}$ \\
\hline
\end{tabular}

\section{Outcome measurements}

Major measurements before and after the intervention trial are shown in Table 4. The primary outcome for the current study is the changes in the knowledge and belief about postpartum practice among the women, which expect the women in intervention group know more about the nutritional requirements in postpartum period and the potential benefit from a balanced diet with appropriate amount of animal food and abundant amount of plant-derived food. The secondary outcome for the current study is the changes in the nutritional status, including both macronutrients and micronutrients level, which reflects the real action of adopting our recommendation in their everyday food intake. The tertiary and the most important outcome is the changes in postpartum recovery and health status, including a promotion for uterine involution and a reduction of postpartum diseases such as puerperal infection, fever, constipation, hemorrhoids, anal fissure, breast disease, oral ulcers, gum bleeding, anemia, pains (headache, heel

Table 4 Overview of the Measurements before and after the Intervention

\begin{tabular}{|c|c|}
\hline Indexes & Assessing methods \\
\hline Nutrition and health knowledge & Questionnaires \\
\hline \multicolumn{2}{|l|}{ Puerperium diet and lifestyle } \\
\hline Diet patterns & 24-hour dietary recording and FFQ \\
\hline Health-related behaviors & Questionnaires \\
\hline Physical activities & Questionnaires \\
\hline \multicolumn{2}{|l|}{ Assessment of nutritional status } \\
\hline $\begin{array}{l}\text { Macronutrients intake (protein, lipid and carbohydrate, and dietary fiber from cereals, } \\
\text { sugar, vegetables, fruits, meat, eggs, milk, soybeans, etc.) }\end{array}$ & $\begin{array}{l}\text { 24-hour dietary recording and FFQ, which include } \\
\text { both food categories and amount }\end{array}$ \\
\hline \multicolumn{2}{|l|}{ Micronutrients intake } \\
\hline Vitamins & $\begin{array}{l}\text { HPLC for vitamin } A \text { and vitamin } D \text {, load test for } B \\
\text { vitamins and vitamin } C\end{array}$ \\
\hline Minierals & AAS for serum calcium, iron and zinc \\
\hline \multicolumn{2}{|l|}{ Nutrient Metabolism } \\
\hline $\begin{array}{l}\text { Blood glucose and lipid profiles, including total cholesterol, HDL-C, LDL-C, } \\
\text { triglycerides }\end{array}$ & Automatic biochemical analyzer \\
\hline \multicolumn{2}{|l|}{ Postpartum recovery and health status } \\
\hline Anthropometric measurements, including height, body weight, and BMI & $\mathrm{BMI}=$ body weight $(\mathrm{kg}) / \mathrm{height}\left(\mathrm{m}^{2}\right)$ \\
\hline $\begin{array}{l}\text { Body recovery, including duration for lochia, amount and duration of postpartum } \\
\text { hemorrhage, degree of uterine involution }\end{array}$ & Diagnosis by specialized obstetricians \\
\hline $\begin{array}{l}\text { Diseases prevalence, including puerperal infection, fever, constipation, hemorrhoids, anal } \\
\text { fissure, breast disease, oral ulcers, gum bleeding, anemia, pains (headache, heel pain, } \\
\text { back pain, leg pain, joint pain, leg cramps, etc.) }\end{array}$ & Diagnosis by specialized doctors \\
\hline Postpartum depression & $\begin{array}{l}\text { Assessed by the Edinburgh Postnatal Depression } \\
\text { Scale }\end{array}$ \\
\hline Milk secretion and neo development & Assessed by specialized doctors \\
\hline
\end{tabular}

FFQ indicates food frequency questionnaires; HPLC, high performance liquid chromatography; AAS, atomic absorption spectrophotometry; HDL-C, high density lipoprotein cholesterol; LDL-C, low-density lipoprotein cholesterol; BMI, body mass index 
pain, back pain, leg pain, joint pain, leg cramps, etc.) and postpartum depression.

\section{Data management and quality assurance}

Data entry will be independently done by two researchers, and then a computer software-based error detection will be carried out to check the consistency of these data. If inconsistency occurs, the original questionnaire will be referred and the error will be corrected via a re-entry.

\section{Ethical approval}

This study will be carried out in accordance with requirements documented in the Declaration of Helsinki. Ethics approval has been obtained from the local Health Department and the research ethics boards of Tongji Medical College, China.

\section{Statistical methods}

Descriptive statistics will be calculated and checked for balance in intervention and control groups in demographic, health and outcome measurements at baseline. Comparisons between intervention group and control group will be performed by Chi-square (categorical variables), $\mathrm{t}$ test (continuous variables, normal distribution) or Mann-Whitney U test (continuous variables, skewed distribution). Final analyses will be undertaken using generalized linear mixed models to investigate changes over time in the two groups in the major outcomes. These models allow for repeated measures and can be used for normally distributed, binomial, and ordinal data [22]. All statistical analyses will be performed using SPSS 12.0 statistical software package (SPSS Inc, Chicago, IL, USA).

\section{Discussion}

It is generally accepted that a balanced diet comprising abundant intake of whole cereals, fruits, vegetables and a suitable amount of fish, meat, eggs and milk is essential for maintaining our health. However, postpartum women in China are traditionally advised to follow a special dietary and lifestyle pattern, which is quite different from the dietary and lifestyle patterns they maintain before and after postpartum period [15]. Several studies have paid attention to explore the relationship of postpartum practice and consequent health problems in Chinese women [23,24]; however, as we know, it is hard to draw a clear causation in cross-sectional studies.

To our knowledge, this study is the first and largest multicenter RCT which focus on the effectiveness of diet and lifestyle intervention on reducing the incidence rate of postpartum diseases and improving health status in postpartum women. This evidence-based study is designed on the basis of data from our previous study in three regions in Hubei province of China $[15,16]$, incorporating with the latest WHO recommendations [19]. The major limitation of this study is that the participants that we will recruit are mainly Chinese Han women, whereas the postpartum practices vary among different national minorities in China. Further research on different minority populations will be very interesting.

We hypothesize that the intervention will reduce the incidence rates of postpartum diseases and improve nutrition and health status due to a balanced diet and reasonable lifestyle in comparison with the control condition. If so, the results of our study will provide especially important evidence for changes in postpartum diet and lifestyle. The fantastic reform in both the concept and action of traditional postpartum practice in China will be expected.

\section{List of abbreviations}

RCT: randomized controlled trial; WHO: world health organization

\section{Acknowledgements}

The authors gratefully acknowledge all the participants for their support. This study was supported by the National Key Technology R\&D Program of China (2008BAI58B07).

\section{Author details}

${ }^{1}$ Department of Nutrition and Food Hygiene and MOE Key Lab of Environment and Health, School of Public Health, Tongji Medical College, Huazhong University of Science \& Technology, 13 Hangkong Road, Wuhan 430030, PR China. ${ }^{2}$ Institute of Human Nutrition, Medical College of Qingdao University, 38 Dengzhou Road, Qingdao 266021, PR China. ${ }^{3}$ Department of Nutrition and Food Hygiene, School of Public Health and Tropical Medicine, Southern Medical University, Guangzhou 510515, PR China. ${ }^{4}$ National Center for Chronic and Noncommunicable Disease Control and Prevention, Chinese Center for Disease Control and Prevention, 27 Nanwei Road, Beijing 100050, PR China. ${ }^{5}$ Hubei Maternal and Child Health Hospital, 745 Wuluo Road, Wuhan 430070, PR China. ${ }^{6}$ Department of chemical and biology, Medical Science College of China Three Gorges University, 8 Daxue Road, Yichang 443002, PR China.

\section{Authors' contributions}

$W B$ and $L L$ is responsible for developing the intervention protocol and drafting the manuscript. LL originated the idea for the study, led on its design, and supervised the project. LL, AM and LM directed the multi-center trial in Central, Northern and Southern China, respectively. $J$ contributed in statistical analysis and quality control of the trial. MX, GS, YO, SW, WY, NW, $Y Z$, JF contributed in participants recruitment and data collection. All authors participated in discussing the design of the study and developing the research protocols. All authors read and corrected draft versions of the manuscript and approved of the final manuscript.

\section{Competing interests}

The authors declare that they have no competing interests.

\section{Received: 31 December 2009}

Accepted: 27 February 2010 Published: 27 February 2010

\section{References}

1. WHO: Postpartum Care of the Mother and Newborn: a practical guide Geneva: World Health Organization 1998.

2. WHO: The world health report 2005: make every mother and child count Geneva: World Health Organization 2005. 
3. WHO: Maternal Mortality in 2000: Estimates Developed by WHO, UNICEF, and UNFPA Geneva: World Health Organization 2003.

4. WHO: Maternal Mortality in 2005: Estimates developed by WHO, UNICEF, UNFPA, and The World Bank Geneva: World Health Organization 2007.

5. Kim-Godwin YS: Postpartum beliefs and practices among non-Western cultures. MCN Am J Matern Child Nurs 2003, 28:74-78, quiz 79-80..

6. Kaewsarn P, Moyle W, Creedy D: Traditional postpartum practices among Thai women. J Adv Nurs 2003, 41:358-366.

7. Chee CY, Lee DT, Chong YS, Tan LK, Ng TP, Fones CS: Confinement and other psychosocial factors in perinatal depression: a transcultural study in Singapore. J Affect Disord 2005, 89:157-166.

8. Chan SM, Nelson EA, Leung SS, Cheung PC, Li CY: Special postpartum dietary practices of Hong Kong Chinese women. Eur J Clin Nutr 2000, 54:797-802.

9. Kartchner R, Callister L: Giving birth. Voices of Chinese women. J Holist Nurs 2003, 21:100-116.

10. Leung SK, Arthur D, Martinson IM: Perceived stress and support of the Chinese postpartum ritual "doing the month'. Health Care Women Int 2005, 26:212-224.

11. Callister LC: Doing the Month: Chinese Postpartum Practices. Global Health and Nursing 2006, 31:390.

12. Matthey S, Panasetis $P$, Barnett B: Adherence to cultural practices following childbirth in migrant Chinese women and relation to postpartum mood. Health Care for Women International 2002, 23:567-575.

13. Chu C: Postnatal experience and health needs of Chinese migrant women in Brisbane, Australia. Ethnicity and Health 2005, 10:33-56.

14. Brathwaite AC, Williams CC: Childbirth Experiences of Professional Chinese Canadian Women. J Obstet Gynecol Neonatal Nurs 2004, 33:748-755.

15. Liu N, Mao L, Sun X, Liu L, Chen B, Ding Q: Postpartum practices of puerperal women and their influencing factors in three regions of Hubei, China. BMC Public Health 2006, 6:274

16. Liu N, Mao L, Sun X, Liu L, Yao P, Chen B: The effect of health and nutrition education intervention on women's postpartum beliefs and practices: a randomized controlled trial. BMC Public Health 2009, 9:45.

17. Amorim AR, Linne YM, Lourenco PM: Diet or exercise, or both, for weight reduction in women after childbirth. Cochrane Database Syst Rev 2007, CD005627.

18. Wolfgang A, Pigeot I: Handbook of Epidemiology Berlin Heidelberg: SpringerVerlag 2005

19. WHO: Pregnancy, Childbirth, Postpartum And Newborn Care: A guide for essential practice, second edition Geneva: World Health Organization 2006.

20. Niederer I, Kriemler S, Zahner L, Burgi F, Ebenegger V, Hartmann T, Meyer U, Schindler C, Nydegger A, Marques-Vidal P, Puder Jj: Influence of a lifestyle intervention in preschool children on physiological and psychological parameters (Ballabeina): study design of a cluster randomized controlled trial. BMC Public Health 2009, 9:94.

21. Raven JH, Chen Q, Tolhurst RJ, Garner P: Traditional beliefs and practices in the postpartum period in Fujian Province, China: a qualitative study. BMC Pregnancy Childbirth 2007, 7:8.

22. Rose SB, Lawton BA, Elley CR, Dowell AC, Fenton AJ: The 'Women's Lifestyle Study', 2-year randomized controlled trial of physical activity counselling in primary health care: rationale and study design. BMC Public Health 2007, 7:166

23. Wang $X$, Wang $Y$, Zanzhou S, Wang J, Wang J: A population-based survey of women's traditional postpartum behaviours in Northern China. Midwifery 2008, 24:238-245.

24. Wang X, Wang Y, Zhou S, Wang J, Wang J, Lofstedt P: Women's postpartum practices and chronic pain in rural China. Matern Child Health J 2009, 13:206-212

\section{Pre-publication history}

The pre-publication history for this paper can be accessed here:http://www. biomedcentral.com/1471-2458/10/103/prepub

doi:10.1186/1471-2458-10-103

Cite this article as: Bao et al:: Diet and lifestyle interventions in postpartum women in China: study design and rationale of a multicenter randomized controlled trial. BMC Public Health 2010 10:103.

\section{Submit your next manuscript to BioMed Central and take full advantage of:}

- Convenient online submission

- Thorough peer review

- No space constraints or color figure charges

- Immediate publication on acceptance

- Inclusion in PubMed, CAS, Scopus and Google Scholar

- Research which is freely available for redistribution

Submit your manuscript at www.biomedcentral.com/submit
Ciomed Central 